Paper resubmitted to Engineering Structures, in April 2005.

\title{
Experimental and Numerical Studies of External Steel Plate Strengthened Reinforced Concrete Coupling Beams
}

R.K.L. $\mathrm{Su}^{\mathrm{a}^{*}}$ and $\mathrm{Y} . \mathrm{Zhu}^{\mathrm{b}}$

a Assistant Professor

b PhD Student

* Corresponding Author

Address: Department of Civil Engineering, The University of Hong Kong, Pokfulam

Road, Hong Kong, China

Fax (852) 25595337

E-mail address $\underline{k l s u @ h k u c c . h k u . h k}$ 


\section{Abstract}

This paper aims to develop a new method for strengthening reinforced concrete coupling beams. Experiments were conducted to test three full-scale RC coupling beams, of which two were strengthened by bolted external steel plates on the side faces of the beams and the other one acted as a control specimen without strengthening. The improvements to strength, deformation and energy dissipation of the external plate strengthened RC coupling beams were observed from the experimental results. Nonlinear finite element analysis was carried out to model the strengthened and non-strengthened coupling beams. The material properties used for concrete and reinforcement in the numerical analysis were validated by the laboratory tests. As experimental study showed that there was a small slip between the bolted connection and the concrete wall pier, a bilinear model was used to simulate the load-slip behaviour of the bolt connections. The model was calibrated by the experimental results from the plate strengthened coupling beams. Numerical parametric study found that the small slip $(>3 \mathrm{~mm})$ between the bolt connection and the concrete wall could significantly affect the load carrying capacity of the bolt connections as well as the structural performance of the strengthened coupling beams. The numerical model developed is very useful for investigating strengthened beams with other configurations and other reinforcement details.

\section{Keywords:}

Coupling beam; Strengthening; Steel plate; Bolt; Strength; Deformation; Ductility; Nonlinear finite element analysis 


\section{Introduction}

Coupled shear walls or core walls are commonly employed as a major lateral loadresisting system in tall building structures in Hong Kong. Due to various architectural constraints and the need for accommodating building services, openings through walls are unavoidable. Coupling beams are required to connect the wall piers and transfer forces between them. The stiffness, strength and ductility of coupling beams have great influences on the overall structural behavior of coupled wall buildings under seismic attack. Local failure of coupling beams may lead to a more serious global failure of the whole lateral load resisting system of the building.

In Hong Kong, most of the reinforced concrete (RC) buildings were built during the last 40 years or so. It is evident that a large number of old building structures are prone to serious material deteriorations due to carbonation, chloride attack of reinforcement, alkali-silica reaction of concrete, and so on. In addition, owing to the inadequacy of the shear design equation in the old design code CP114 [1], these old buildings are likely to be deficient in shear reinforcement. Recent seismic hazard studies [2-3] have shown that Hong Kong is located in a region of low-to-moderate seismicity. Many existing building structures without provisions for resisting earthquake loads might no longer be considered to be up to the new standard due to increased-load specifications in the seismic code. A large number of RC coupling beams might require rehabilitation or retrofitting to increase their strength, stiffness and energy dissipation capability.

Many studies have focused on the structural performances of conventional and nonconventional RC coupling beams. Paulay [4] studied the behavior of conventional RC 
coupling beams in shear wall structures. He pointed out that the behavior of coupling beams was different from that of ordinary beams, especially when the span-to-depth ratio was low. Harries [5] reviewed the large-scale experimental investigations of conventional RC coupling beams and demonstrated that the coupling beam ductility demand often exceeded the expected available ductility. Harries et al. [6] had reported their research on seismic retrofit of RC coupling beams using steel plates. In their research the retrofitting measures involved using a number of different attachment ways to fix the thin steel plates to one side of the coupling beams to enhance their shear performance. Recently, Lam et al. [7-8] proposed to enhance the deformation and ductility capacities of RC coupling beams by utilizing the composite action between steel plate and RC. However, their suggestion of embedding a steel plate in a RC coupling beam could only be used in new constructions. For existing shear wall structures in Hong Kong, where the coupling beams were designed without any seismic considerations, the increase in strength by attaching external steel plates on both sides of the beam is proposed.

There are basically two methods for strengthening or stiffening existing RC members. The first method is to attach advanced composites, such as glass fibre reinforced plastic (GFRP) and carbon fibre reinforced plastic (CFRP), onto the tension surface or the side faces of the members. Teng et al. [9] conducted a comprehensive review of using advanced composites to strengthen RC structures. These composites are generally capable of increasing the ductility and ultimate load resistance but are prone to peeling and delamination under shear stresses, and debonding under cyclic loading. Design procedures were developed to prevent rupture and debonding failures [10-11]. Sheikh [12] reported the research on retrofit of beams, slabs, walls and columns with fibre reinforced 
plastic (FRP). His results indicated that flexural strength of the damaged slabs, shear resistance of the damaged beams and seismic resistance of the columns could be improved.

The second method for strengthening or stiffening existing RC components is to attach steel plates to the external surfaces of the structural components by means of adhesive bonding or bolting. Oehlers and Seracino [13] evaluated the design of steel plated RC structures. Bolting can avoid any uncertainty over long-term durability of adhesives and the problem of peeling associated with high stress concentrations and cyclic loadings. Furthermore, bolting can provide limited confinement for the concrete core by allowing a triaxial stress state to develop in bolting area and can avoid the need for surface preparation on site. However bolting construction has the drawbacks of possible weakening of the concrete components due to drilling of bolt holes through the concrete and the associated more expensive labor cost.

Several researchers have studied the ways to strengthen the flexural resistance of concrete beams by means of adhesively bonded or bolted steel plates on the soffit of the beams. Subedi and Baglin [14] conducted an investigation on strengthening the shear capacity of concrete beams by bolted steel plates on the external surfaces and showed enhancements of shear and flexural strengths of the beams. Uy [15] presented a set of tests for RC columns strengthened with bolted, or glued and bolted steel plates under both axial and flexural loads. His investigation illustrated that adding steel plates to RC columns could increase both the stiffness and strength of the member. However, the increase in column stiffness is not desirable after retrofit, as additional seismic load would be attracted to the superstructure. Barnes et al. [16] studied the effects of attaching the steel plates to the 
external surfaces of concrete beams by bonding or bolting. Their research mainly focused on shear strength enhancement of RC beams. By introducing a gap at the bottom of the plating system, Wu et al.[17-19], on the other hand, developed a steel plate retrofit system that can increase the ductility of RC columns without increasing the stiffness of the member.

Although attaching steel plates to external surfaces of RC beams have been shown to be able to improve the strength of simply supported and continuous beams, this technique has not been fully explored and extended to strengthening coupling beams that are structurally different from ordinary floor beams. Detailed numerical analysis of this type of retrofitted beams is rare. In this paper, experimental and numerical studies on coupling beams strengthened by steel plates attached on the vertical faces (web) of the beams were conducted. The steel plates were attached to the side faces of the specimens by means of bolting. The bolts were designed to transfer all the bending and shear forces from the steel plate to the wall anchor by using bolt group theory. The positions of the bolts through beam and walls were carefully selected such that the boltholes would not cut across the main reinforcement of the beam and walls, whereas the steel plates could be securely attached on the vertical faces by tightening the bolts. The improvements to strength, deformation and energy dissipation of the external plate strengthened RC coupling beams will be presented in the following sections of this paper. The variations of shear load to chord rotation angle of the beams and the force distributions of the bolts are obtained from laboratory tests. The results are compared with those from the nonlinear finite element analysis (NLFEA). Numerical parametric study was conducted to study the effects of slip between the bolt connection and the concrete wall on the load 
carrying capacity of the bolt connections as well as the structural performance of the strengthened coupling beams.

\section{Experimental Program}

\subsection{Description of test specimen}

Three RC coupling beam specimens having the same dimensions and reinforcement details but different attached steel plate arrangements were tested. The first specimen CB1 with conventional reinforcement detail was a control beam, and the other two beams (CB2 and CB3) were strengthened with bolted steel plates with different thickness as shown in Table 1. The specimen dimensions and reinforcement details of CB2 and CB3 are displayed in Figure 1, and the material properties are shown in Table 2.

The control specimen CB1 was designed according to BS8110 [20] to ensure that shear failure would occur prior to flexural failure. For the other two specimens (CB2 and CB3), where bolted steel plates were attached, socket anchorages were incorporated at specific locations prior to concreting. All steel plates used were $1250 \mathrm{~mm}$ long and $300 \mathrm{~mm}$ deep. The locations of the anchorages of the steel plates for the two specimens are shown in Figure 2. After curing of concrete, the external plates were fixed to the cast-in sockets with Grade 8.8 bolts of diameter $20 \mathrm{~mm}$. Slightly larger clearance holes of $22 \mathrm{~mm}$ diameter were provided for tolerances in fabrication and drilling of holes in the steel plates. Once all the bolts were fastened, a torque of $100 \mathrm{Nm}$ was applied to tighten the bolts to achieve a good connection. The bolts were then welded to the plate in order to prevent any slip within the clearance hole. 
Electrical resistance linear strain gauges and rosette strain gauges were attached to the reinforcement and the external steel plates, respectively, to investigate the strain as well as the internal stress and force distributions. Linear variable displacement transducers (LVDTs) were instrumented to capture the chord rotation and the sectional curvature profiles of the coupling beams. Figure 3. shows the arrangement of linear variable displacement transducers (LVDTs) and rosette strain gauges of specimen CB3.

\subsection{Test Setup}

Figures 4 and 5 show the test setup, which was designed by Kwan and Zhao [21], and the loading sequence. Loading was applied from a $500 \mathrm{kN}$ actuator to the top end of each $90^{\circ}$ rotated specimen through a rigid arm with the line of action passing through the beam center. In this way, the coupling beam was loaded with a constant shear force along the span and a linearly varying bending moment with the contra-flexure point at mid-span. In order to simulate the real situation in which the wall piers at the two ends of a coupling beam remain parallel under deflections of the building, a parallel mechanism was installed to connect the upper rigid arm with the lower structural steel beam fixed on the floor. Reversed cyclic loading was first applied to each specimen in a load controlled cycle up to $75 \%$ of the theoretical ultimate shear capacity $\left(V_{u}^{*}\right)$. The subsequent cycles were displacement-controlled, in which the specimen was displaced to nominal ductility factor $\left(\mu_{n}\right) 1$ for one cycle, then to each successive nominal ductility factor for two cycles as shown in Figure 5. Beam rotations $(\theta)$, defined [22] as the differential displacement between the two beam ends in the loading direction divided by the clear span $(l)$, were calculated using the displacements measured by LVDTs. The nominal yield rotation $\left(\theta_{y n}\right)$ 
at $\mu_{n}=1$ was obtained using the average of the $\theta$ values corresponding to the positive and the negative loads at $0.75 V_{u}^{*}$ in the first cycle divided by the factor 0.75 . The actual yield rotation $\left(\theta_{y}\right)$ was later obtained in the same manner from the maximum measured shear

$\left(V_{\max }\right)$. The test was terminated when the peak load obtained in the first cycle of a nominal ductility level fell below the lesser of $0.8 V_{u}^{*}$ and $0.8 V_{\max }$, and the test specimen was then considered to have failed.

\section{Experimental Results and Discussion}

\subsection{Strength and Ductility}

The performance of the specimens was evaluated through the measured strains and LVDT data, and by the observed damage and crack patterns. Table 3 summarizes the experimental results of all the three specimens. The attached plates increased both the ultimate capacity and deformability of specimen beams CB2 and CB3. The ultimate shear $V_{u}^{*}$ and the ultimate measured chord rotation angle $\left(\theta_{u}\right)$ for CB2 were increased by $37 \%$ and $23 \%$, respectively, whereas for $\mathrm{CB} 3$ were increased by $70 \%$ and $62 \%$, respectively. The maximum nominal ductility factors, which are defined as the ultimate rotations divided by the nominal yield rotations $\left(\mu_{n}=\theta_{u} / \theta_{y n}\right)$, for $\mathrm{CB} 1$ and $\mathrm{CB} 2 \& \mathrm{CB} 3$, respectively, are equal to 6.2 and 5.1. The maximum ductility factors, which are defined as the ultimate rotations divided by the notional yield rotations obtained from the test ( $\mu=\theta_{u} / \theta_{y}$ ), for $\mathrm{CB} 1, \mathrm{CB} 2$ and $\mathrm{CB} 3$ are equal to $4.0,3.8$ and 3.7 , respectively. The attached plates slightly reduced the ductility of the coupling beams. This is because by attaching the ductile steel plates onto the beams, the increase in the notional yield chord 
rotation angle $\left(\theta_{y}\right)$ is slightly larger than that of the ultimate measured chord rotation angle $\left(\theta_{u}\right)$. Ductility defined as $\theta_{u} / \theta_{y}$ is therefore reduced by adding the steel plates. Furthermore, the attached steel plates increased both the stiffness and the deformation capacity of the beams. The excessive deformation caused crushing of concrete under compression and led to ultimate failure of the beams.

\subsection{Load-Chord Rotation Curves}

Figure 6 shows the applied shear force against the chord rotation angle for all the specimens. It can be seen that the bending stiffness of all the plate-strengthened coupling beams was increased when compared with the control specimen. The shear force - chord rotation curve of $\mathrm{CB} 1$ exhibits substantial pinching, especially at large deflection amplitudes. Such pinching leads to rapid stiffness degradation and less energy dissipation. The shear force - chord rotation curves of $\mathrm{CB} 2$ and $\mathrm{CB} 3$ are similar and have less pinching, better energy dissipation capacity (more than double) and more stable hysteretic loop when compared with that of CB1. Figure 7 shows the relationships of cumulative energy dissipation with the cumulative displacement. Comparing the energy dissipated values of $\mathrm{CB} 2$ and $\mathrm{CB} 3$, it is seen that among the two specimens, the beam strengthened with thick steel plate dissipated more energy. The reasons are that the ductile steel plates possessed better deformability and higher energy dissipation via plastic deformation, and resisted most of the applied load as the ductility factor increases.

The results reveal that the external attached steel plates can significantly improve the inelastic behavior in terms of higher energy dissipation and lower strength degradation of the coupling beams. 


\subsection{Stiffness degradation}

The degradations of stiffness for all the specimens are analyzed and shown in Figure 8. In the figure, the initial stiffness $K_{0}$ is defined as the ultimate shear force divided by the notional yield displacement and $K_{i}$ is the instantaneous secant stiffness at a certain displacement. The initial stiffnesses $K_{0}$ for $\mathrm{CB} 1, \mathrm{CB} 2$ and $\mathrm{CB} 3$ are $30.60 \mathrm{kN} / \mathrm{mm}$, $40.82 \mathrm{kN} / \mathrm{mm}$ and $37.46 \mathrm{kN} / \mathrm{mm}$, respectively. Although CB3 was strengthened with thick steel plate, it has lower initial stiffness than that of CB2 due to immature tearing of welds of the bolt connections of CB3. Because of insufficient leg length, some of the fillet welds between the bolts and the steel plates were torn during the test when the specimen reached its ultimate load (at nominal ductility +2 ). From Figure 8 , it can be seen that the strengthened coupling beams CB2 and CB3 have lower stiffness degradation rate and higher displacement capacity than the conventional RC coupling beam CB1.

\subsection{Crack and Damage Patterns}

The crack patterns in the wall piers of all the specimens were similar. Only minor cracks were observed. Figure 9 shows the crack patterns at failure of all the coupling beams. For specimens $\mathrm{CB} 2$ and $\mathrm{CB} 3$, the external plates have been taken away for displaying the crack patterns of concrete along the span of the beams. Plastic hinges adjacent to the beam-wall joints and spalling of concrete along the longitudinal reinforcement can be observed in $\mathrm{CB} 1$. The damage mode can be classified as shear flexural failure. For $\mathrm{CB} 2$, cracks were evenly distributed along the span of the coupling beam and no significant plastic hinge can be observed. The row of bolts along the span of the coupling beam could prevent local buckling of the thinner steel plate $(3 \mathrm{~mm})$ but led to serious concrete 
damage at the failure stage. The bolt arrangement in coupling beams should be further studied to come up with a procedure for optimum design of bolt groups. For CB3, plastic hinges formed at the ends of the beam can be observed. The thicker steel plate $(6 \mathrm{~mm})$ can effectively mitigate buckling of the plate. As the increasing of the ductility factor, the concrete cover to the main reinforcement of the beam gradually spalled off due to increasing compressive force developed along the beam. Serious crushing of concrete under compression led to ultimate failure of the beam.

\subsection{The Behaviors of External Steel Plates}

The stress, strain and internal force distributions of the external steel plates can be determined by analyzing the data obtained from the rosette strain gauges attached on the plate surfaces as well as observing the macro-deformations of the steel plates. The shear and axial strains on the steel plates were first calculated from the measured strains. Then by assuming linear variation of strains between the strain gauges and invoking the stressstrain relationship of steel, the internal forces at each section can be calculated accordingly. Figure 10 shows the variations of the internal shear and axial forces at midspan of the external steel plates. The results reveal that the steel plates for CB2 and CB3 took up increasingly more shear loads as the beam rotation increases. The plates sustained almost all of the shear loads when the nominal ductility factor was higher than 3.

For $\mathrm{CB} 2$, the shear resistance of the steel plate reached its maximum capacity after nominal ductility factor +2 . This was because local yielding and buckling of the steel plate had occurred and limited its load carrying capacity. Owing to elongation of the 
concrete beam under cyclic loads, tensile forces were developed in the steel plate when approaching the peak load at each positive and negative cycle. When the tensile stress induced in the steel plate had reached its yield stress (after nominal ductility factor +2 ), permanent plastic deformation occurred and caused an extension of the steel plate. As a result, the span length of the steel plate was longer than that of the reinforced concrete counterpart under the next reversed cycle. When the chord rotation angle was reduced to zero, the strain compatibility between the reinforced concrete and the steel plate resulted in compression developed in the steel plate and tension induced in the reinforced concrete. For CB3, the shear force taken by the steel plates increased with that of the nominal ductility factor whereas the axial force variation was not stable due to immature tearing of some of the weld connections between the bolts and the steel plate. As a result, energy dissipated by the steel plate in CB3 was lower than that of CB2.

During the test, the external steel plates took the combined bending, shear and axial forces. The induced diagonal compressive forces caused local buckling instability of the plate when the applied loads were greater than the critical limit. This local buckling phenomenon is known as unilateral constraint buckling problem and is critical for external plate strengthened coupling beam under reversed cyclic seismic actions. Figure 11 shows the local buckling modes of the external steel plates at failure of CB2 and CB3. The local buckling occurred at the steel plates near the beam-wall joints. As thinner steel plates were used in $\mathrm{CB} 2$ compared with that of $\mathrm{CB} 3$, a more serious local buckling occurred in $\mathrm{CB} 2$ than in $\mathrm{CB} 3$ despite that additional bolts had been fixed along the beam span of CB2 to control buckling. In spite of buckling of steel plates, no significant loss in strength was found for $\mathrm{CB} 2$ and $\mathrm{CB} 3$. It is because the compressive force originally taken 
up by the steel plate was transferred to concrete after plate buckling. Provided that concrete could have reserved capacity to take up the additional compressive load, the detrimental effects due to plate buckling on the beams would be relatively small. It should be mentioned that Smith and his co-researchers [23-27] had conducted significant theoretical and experimental works on unilateral buckling of steel plates bolted in retrofitted concrete beams. However, theoretical study of the present type of local buckling under combined in-plane bending and shear forces has yet to be studied.

\subsection{The Force Distributions of Bolts}

Based on the strains measured from the rosette strain gauges attached on the surface of the steel plates and the stress-strain relationship of steel, the internal stress at the cross sections of the steel plate were calculated. The bolt forces were then evaluated by considering force equilibrium of free body diagram, from the left side to the right side of the steel plate. Table $4 \mathrm{a}$ shows the bolt force distribution at the peak load of specimen CB2. It can be observed that the bolt forces at the span of specimen CB2 (Bolts 7-9) are much smaller than the bolt forces at the wall anchorage (Bolts 1 and 6). The bolt forces at the interior locations of the bolt group at the wall anchorage (Bolts 3 and 4) are also relatively small. The results indicate that the bolts at the internal part of the bolt group and at the beam span have little effects on the force transfer between the steel plate and the reinforced concrete. However, the bolts at the beam span are important in preventing plate buckling. Table $4 \mathrm{~b}$ shows the bolt force distributions of specimen CB3. Similar observation has been found when the bolt forces at the interior locations are much smaller than the bolt forces at the corner locations of the bolt group. It is noted that as the 
maximum shear force taken by the bolts was $40 \mathrm{kN}$, which was much less than the shear capacity of $91 \mathrm{kN}$, all the bolts were deformed elastically. Based on the experimental observations, the most effective arrangement of the bolt group is to keep the four corner bolts at the wall anchorage and remove the rest of the bolts. This is because fewer the number of holes drilled through the shear wall, the less the impairment to the integrity of the RC members as well as the lower the construction expenses would be resulted in.

\section{Nonlinear Finite Element Analysis}

\subsection{Concrete Material Model and Modeling of the Bolted Connections}

The two-dimensional non-linear finite element package ATENA [28] was used to analyze the load-deflection behaviours and the bolt force distributions of the steel plate strengthened coupling beams. In this analysis, the non-linearity due to the materials and the geometric deformations has been considered.

The non-linear concrete material model used in the subsequent analyses considered the following factors (1) non-linear behavior in compression including hardening and softening, (2) fracture of concrete in tension based on nonlinear fracture mechanics, (3) biaxial strength failure criterion, (4) reduction of compressive strength after cracking, and (5) reduction of the shear stiffness after cracking (variable shear retention). The failure envelope of concrete in the biaxial stress state is described by means of the effective stress and the equivalent uni-axial strain [29]. 
The complete constitutive model of concrete is shown in Figure 12. The material state indices shown in Figure 12 are used to indicate the state of concrete damage during numerical analysis. The peak stresses in compression $f_{c}^{\prime e f}$ and in tension $f_{t}^{\prime e f}$ are calculated according to the failure envelope of concrete [29]. In the first state (Index No. 1), the behavior of concrete in tension without crack is assumed to be linear elastic.

In the second state (index No. 2), after formation of tension cracks, a fictitious crack model based on a crack opening law and fracture energy, which was derived experimentally by Hordijk [30], is used and can be expressed as,

$$
\frac{\sigma}{f_{t}^{\prime e f}}=\left\{1+\left(\frac{3 w}{w_{c}}\right)^{3}\right\} \exp \left(-6.93 \frac{w}{w_{c}}\right)-\frac{10 w}{w_{c}} \exp (-6.93)
$$

and $w_{c}=5.14 \frac{G_{f}}{f_{t}^{\prime e f}}$

where $w$ is the crack opening displacement, $w_{c}$ is the crack opening at the complete release of stress and $\sigma$ is the normal stress in the crack (crack cohesion). $G_{f}$ is the fracture energy needed to create a unit area of stress-which has been expressed as Eq. (3) by Vos [31].

$$
G_{f}=0.000025 f_{t}^{\prime e f}[M N / m]
$$

The crack opening displacement $w$ can be related to the total crack opening displacement within the crack band according to Eq. (4) [32],

$$
w=\varepsilon_{c r} L_{t}^{\prime}
$$


where $\varepsilon_{c r}$ is the crack opening strain, which is equal to the strain normal to the crack direction in the cracked state after the complete stress release and $L_{t}^{\prime}$ is the band size of the element in tension.

In the third state (Index No.3), the stress-strain formula recommended by CEB-FIP Model Code 90 [33] was adopted for compression before the peak stress.

$$
\sigma_{c}=f_{c}^{\prime e f} \frac{k x-x^{2}}{1+(k-2) x}, \quad x=\frac{\varepsilon}{\varepsilon_{c}}, \quad k=\frac{E_{0}}{E_{c}}
$$

where $\sigma_{c}$ is the concrete compressive stress, $x$ is the normalized strain, $\varepsilon$ is the concrete strain, $\varepsilon_{c}$ is the strain at the peak stress $f_{c}^{\prime e f}, k$ is a shape parameter, $E_{0}$ is the initial elastic modulus and $E_{c}$ is the secant elastic modulus at the peak stress.

In the fourth state (Index No. 4), the compressive stress after the peak stress, the softening law in compression is assumed to be linearly descending. The model of strain softening in compression is based on dissipated energy theory [34].

Extensive concrete compression and tension tests [35-38] have been conducted at The University of Hong Kong to study the stress-strain relationship, elastic modulus, Poisson's ratio and tensile strength of normal strength and high strength concrete produced in Hong Kong. Their studies revealed that locally mixed concrete, when compared with those produced from other places has a relatively small initial elastic modulus and a larger peak strain values. This implies that the stress-strain curves for concrete in Hong Kong would be somewhat distorted and shifted to the right side when compared with the stress-strain curves of concrete from other countries with the same 
compressive strength. Furthermore, concrete produced in Hong Kong is found to be more deformable under the same stress level and absorb more energy during deformation. The local concrete properties of the initial elastic modulus $E_{c}$ and the peak strains $\varepsilon_{c}$ used in NLFEA were estimated by the following equations,

$$
\begin{gathered}
E_{c}=6500 f_{c u}^{1 / 3} \\
\varepsilon_{c}=\frac{3.46 f_{c u}^{\frac{3}{4}}}{E_{c}}
\end{gathered}
$$

Accurate modeling of the anchor bolts in the present study is necessary in order to simulate the load-slip effect of the cast-in steel bolts [39]. In this study, a bi-linear model (as shown in Figure 13) is chosen to simulate the load-slip behavior of a $20 \mathrm{~mm}$ diameter cast-in steel bolt. In this figure, the inner circular finite element mesh represents the shank of the steel bolt. The outer ring in the finite element mesh having bi-linear softening material is used to model the load-slip behaviour of the bolt connections. At first, the conventional RC specimen CB1 was modeled by NLFEA. The results were then compared with the experimental results to validate the material parameters for concrete and steel bars used in the NLFEA. After that, finite elements related to the steel plate were added to the model. As the material properties of steel plate are well defined, the only variable is the stiffness (load-slip behaviour) of the bolt connections. This single variable was then calibrated against the experimental results of $\mathrm{CB} 2$ and $\mathrm{CB} 3$. The calibrated stiffness of the load-slip curve (as shown in Figure 13) is found to be slightly higher than that of Ahmed [39]. This is considered reasonable as the bolts used in the present study were fastened into steel cast-in sockets (see Figure 2) which have higher 
stiffness than the cast-in bolts without socket as used by Ahmed. It is expected that the present connection detail have higher stiffness than other fastening connections which may be used in practices by installing bolts through pre-drilled holes in the concrete without socket.

\subsection{Shear Force and Chord Rotation Angle Curves}

The variations of shear force and chord rotation angle were computed by the NLFEA for all the specimens. The finite element mesh configuration of CB2 is shown in Figure 14. It is noted that $\mathrm{CB} 1$ is a control specimen without attachment of the steel plates to the RC beam. Figure 15 shows the load-rotation curve of CB1 obtained from the numerical analysis. The numerical result agrees well with that of experimental study. Based on that model, small ring finite element meshes with non-linear property as shown in Figure 13 were added to simulate the load-slip effect of the bolted connections. Elasto-plastic plane elements were used to model the steel plate. The finite element models for specimens $\mathrm{CB} 2$ and $\mathrm{CB} 3$ were then developed. It can be seen that the envelope curves determined by the NLFEA for specimens CB2 and CB3 are consistent with the experimental results. The peak loading, the stiffness and the non-linear load-rotation behaviors could be correctly simulated.

\subsection{Comparison of Numerical and Experimental Results of Bolt Forces}

Figures 16 and 17 show the comparison of bolt forces obtained from numerical and experimental results. Basically, the numerical results can correctly simulate the loading histories of the bolts. The maximum deviation from the experimental results at peak 
loadings is approximately $20 \%$. As the predicted bolt forces could be quite sensitive to the change in load-slip model used in the numerical analysis, numerical parametric study based on the calibrated finite element model is conducted to investigate the effect of varying the bolt stiffness on the structural performance of the strengthened coupling beams.

\subsection{Parametric Study of Varying the Stiffness of the Bolt Connections}

The stiffness of bolt connection that could significantly affect the structural performance of the strengthened coupling beam is a key concern in this study. The connection stiffness depends on various factors such as the type of anchor bolts used, the thickness of the specimens and the workmanship for installation of the bolts. These factors, however, are difficult to be quantified in the design stage. In order to investigate the effect of varying the bolt connection stiffness on the overall stiffness as well as the post-peak behavior of the strengthened beam, case studies for specimen CB3 using NLFEA was carried out. In Case 1, rigid-plastic connection was used to obtain the upper bound solution. In the other cases, gradually reduced connection stiffness was used in the finite element analysis. Apart from the change in connection stiffness, other structural parameters are kept to be the same as those of specimen CB3. Figure 18(a) shows the load-slip curves of the bolt connection used in the analysis. Figure 18(b) presents the load-rotation curves of the strengthened beams obtained by the NLFEA. The curve from the real model CB3 using the actual connection stiffness is also shown in Figure 18(b) for comparison. It is clear that the capacity as well as the ultimate rotation of the beams is highly dependent on the bolt stiffness. By using rigid-plastic bolt connection (Case 1), the peak load can go up to 
$495 \mathrm{kN}$, which is increased by $32 \%$ when compared with the actual bolt stiffness used in CB3. In Case 4 when the stiffness is reduced by 5 times when compared with the actual stiffness used in CB3, the peak load is reduced to $257 \mathrm{kN}$, which is similar to that of the non-strengthened specimen CB1. Accompanied with the changes in peak loading, there appear certain reductions in the initial stiffness as well as the yield displacement for all the specimens due to the reduction of the bolt stiffness. This is because good bolt connection with stronger stiffness could enhance the steel plate to take up more shear force from the reinforced concrete before and especially after the peak loading. Numerical results clearly indicate that small slip $(>3 \mathrm{~mm})$ between the bolt connection and the concrete wall could have detrimental effects on the load carrying capacity of the bolt connections as well as the structural performance of the strengthened coupling beams. Further experimental investigations may need to be conducted to develop more accurate load-slip models for the common types of anchor bolts used in construction industry.

\section{Conclusions}

The paper presents a study of strengthening RC coupling beams by bolted steel plates on side faces of the web. The experimental and numerical findings are summarized as follows:

1. External steel plate attachment by bolted connections could considerably enhance the strength and deformation capacity of coupling beams under reversed cyclic loadings. 
2. The attached external steel plates with bolted connections could steadily sustain most of the shear force after reaching the peak loading of the coupling beam. The good inelastic responses of the strengthened coupling beams support the use of bolted connections for the case of high seismic loading and displacement demands.

3. Before yielding of the plate, axial tension would develop in the steel plate. After yielding had occurred, axial force would alternate from compression to tension and then back to compression in half of each loading cycle.

4. The phenomenon of unilateral constraint local buckling of the external steel plate under reversed cyclic loading was observed. However, there was no significant loss in strength for the retrofitted beams (CB2 and CB3) after buckling. It is probably because the compressive force originally resisted by the steel plate was transferred to the concrete after bucking. Further experimental and numerical studies may be conducted to quantify this effect.

5. Very good agreements between the experimental and NLFEA results are found. The NLFEA has been shown to be able to accurately predict the strength, stiffness and load-rotation behavior of the steel plate strengthened coupling beam.

6. The proposed method for considering bolt connection load-slip effect can correctly simulate the load-rotation behavior of the coupling beams as well as the loading history of the bolt forces. The numerical model developed is very useful 
for design of strengthened beams with other configurations and other reinforcement details.

7. Numerical parametric study reveals that the small slip $(>3 \mathrm{~mm})$ between the bolt connection and the concrete wall could have detrimental effects on the load carrying capacity of the bolt connections as well as the structural performance of the strengthened coupling beams. Further experimental investigations may need to be conducted to develop more accurate load-slip models for the common types of anchor bolts used in construction industry. Furthermore, the type of bolts used, the connection details and the stiffness of the bolt groups should be well thoughtout in design stage for RC coupling beams strengthened with bolted external steel plates.

This new application of using steel plate to strengthen RC coupling beams is still under development, the design procedure will be provided after conducting more experimental or numerical testing of specimens with different span-to-depth ratio as well as different steel plate and bolt arrangements.

\section{Acknowledgements}

The research described here has been supported by The University of Hong Kong through the Large Item Grant and by the Research Grants Council of Hong Kong SAR (Project No. HKU7129/03). Special thank is expressed to Dr. H.J.Pam for her permission to use the licensed finite element package ATENA for the numerical analysis. 


\section{References}

[1] CP114. The structural use of reinforced concrete in buildings. Part 2, The Council for Codes of Practice British Standards Institution, London, 1969.

[2] Chandler AM, Chan LS, Lam NTK. Deterministic seismic hazard parameters and engineering risk implications for the Hong Kong region. J Asian Earth Sci, 2002; 20(1):59-72.

[3] Chandler AM, Lam NTK. Scenario predictions for potential near-field and far-field earthquakes affection Hong Kong. J Soil Dyn Earthquake Eng 2002; 22(1):29-46.

[4] Paulay T. Coupling beams of reinforced concrete shear walls. J Struct Division, Proceedings of the ASCE 1971; ST(3):843-862.

[5] Harries KA. Ductility and deformability of coupling beams in reinforced concrete coupled wall. J Earthquake Spectra 2001; 17(3):457-478.

[6] Harries KA, Cook WD, Mitchell D. Seismic retrofit of reinforced coupling beams using steel plates. ACI SP-160; June 1, 1996. p. 93-114

[7] Lam WY, Su RKL, Pam HJ. The performance and design of embedded steel composite coupling beams. In: Proceedings of the Structural Engineers World Congress (SEWC2002) Yokohama, Japan, October 9-12; 2002. p. 365-373.

[8] Lam WY, Su RKL, Pam HJ. Ductility and strength of embedded steel composite coupling beam. Inter J Adv Eng Struct 2003; 6(1):23-35.

[9] Teng JG, Chen JF, Smith ST, Lam L. FRP: strengthened RC structures. Wiley Publications, 2002. 
[10] Chen JF, Teng JG. Shear capacity of fiber-reinforced polymer-strengthened reinforced concrete beams: Fiber reinforced polymer rupture. J of Struct Eng, ASCE 2003; 129 (5): 615-625.

[11] Chen JF, Teng JG. Shear capacity of FRP-strengthened RC beams: FRP debonding. Construction and Building Materials 2003; 17 (1): 27-41.

[12] Sheikh SA. Performance of concrete structures retrofitted with fibre reinforced polymers. J Eng Struct 2002; 24:869-879.

[13] Oehlers D, Seracino R. Design on FRP and steel plated RC structures. Elsevier Publications, 2004.

[14] Subedi NK, Baglin PS. External plate reinforcement for concrete beams. J Struct Eng 1998;124(12):1490-1495.

[15] Uy B. Strength of reinforced concrete columns bonded with external steel plates. Magazine of Concrete Research 2002; 54(1):61-76.

[16] Barnes BA, Baglin PS, Mays GC, Subedi NK. External steel plate systems for the shear strengthening of reinforced concrete beams. J Eng Struct 2001;23:1162-1176

[17] Wu YF, Griffith MC, Oehlers DJ. Improving the strength and ductility of rectangular RC columns through composite partial-interaction: Tests. J Struct Eng, ASCE 2003; 129(9): 1183-1190.

[18] Wu YF, Griffith MC, Oehlers DJ. Numerical simulation of steel plated RC columns. Comp and Struct 2004; 82(4-5): 359-371. 
[19] Wu YF, Oehlers DJ, Griffith MC. Partial interaction analysis of composite beam/column members. Mech of Struct and Mach 2002; 30(3): 309-332.

[20] BS8110. Part 1, Code of practice for design and construction, structural use of concrete. British Standards Institution, London. 1985.

[21] Kwan AKH, Zhao ZZ. Non-linear behavior of reinforced concrete coupling beams. The Fifth International Conference on Tall Buildings, Hong Kong. 1998, p. 410-415.

[22] Su RKL, Zhu Y. The chord angle demand of coupling beams under potential seismic loads in Hong Kong. In: The Second International Conference on Engineering Mechanics and Computation, Cap Town. South Africa. 2004.

[23] Smith ST, Bradford MA, Oehlers DJ. Buckling tests on steel plates restrained at discrete points in the retrofit of reinforced concrete beams. Proceedings of the Institution of Civil Engineers-Structures and Buildings 2001; 146 (2): 115-127.

[24] Smith ST, Bradford MA, Oehlers DJ. Unilaterial buckling of elastically restrained rectangular mild steel plates. Computational Mechanics 2000; 26 (4): 317-324.

[25] Bradford MA, Smith ST, Oehlers DJ. Semi-compact steel plates with unilateral restraint subjected to bending, compression and shear. J Constructional Steel Research 2000; 56 (1): 47-67.

[26] Smith ST, Bradford MA, Oehlers DJ. Local buckling of side-plated reinforcedconcrete beams. I: Theoretical study. J Struct Eng, ASCE 1999; 125 (6): 622-634.

[27] Smith ST, Bradford MA, Oehlers DJ. Local buckling of side-plated reinforcedconcrete beams. II: Experimental study. J Struct Eng, ASCE 1999; 125 (6): 635-643. 
[28] Cervenka V, Cervenka J. User's manual for ATENA 2D. Cervenka Consulting, Prague, Czech Republic. 2002.

[29] Kupfer H, Hilsdorf HK and Rusch H. Behavior of concrete under biaxial stress, Journal ACI, Proc. 1969; 66(8): 656-666.

[30] Hordijk DA. Local approach to fatigue of concrete. Doctor dissertation (1991), Delf University of Technology, The Netherlands, ISBN 90/9004519-8.

[31] Vos E. Influence of loading rate and radial pressure on bond in reinforced concrete. Dissertation (1991), Delft University, pp.219-220.

[32] Bazant ZP, Oh BH. Crack band theory for fracture of concrete. Materials and Struct, RILEM, 1983,Vol. 16, p155-177.

[33] CEB-FIP Model Code 1990, First Draft, Committee Euro-International du Beton, Bulletin d'information No.195,196, Mars.

[34] Mier JGM van. Multiaxial strain-softening of concrete, Part I: fracture. Materials and Struct, RILEM, 1986,Vol. 19, No.111.

[35] Cheng LSB. Stress-strain curve of concrete under compression. Final Year Project (2000-2001), Department of Civil Engineering, The University of Hong Kong.

[36] Lee PKK, Kwan AKH, Zheng W. Tensile strength and elastic modulus of typical concrete made in Hong Kong. Trans Hong Kong Inst Eng 2000; 7(2):35-40.

[37] Wong KY, Kwan AKH. Some mechanical properties of high-strength concrete in Hong Kong. Trans Hong Kong Inst Eng 2000;7(3):13-18. 
[38] Kwan AKH, Lee PKK, Zheng W. Elastic modulus of normal and high strength concrete in Hong Kong”, Trans Hong Kong Inst Eng 2001; 8(2):10-15.

[39] Ahmed M. Strengthening of reinforced concrete beams by bolting steel plates to their sides. Master's Thesis. Department of Civil \& Environmental Engineering, The University of Adelaide, Australia. 1996. 

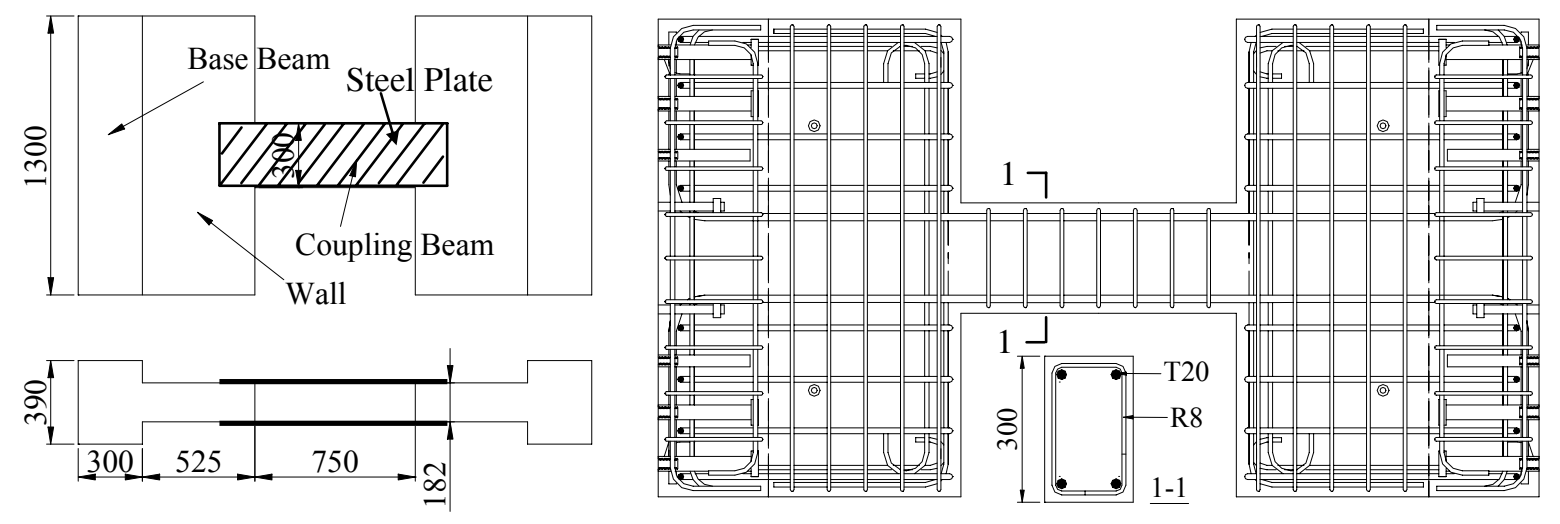

Figure 1. Configuration and Reinforcement Detail of Specimens CB2 and CB3

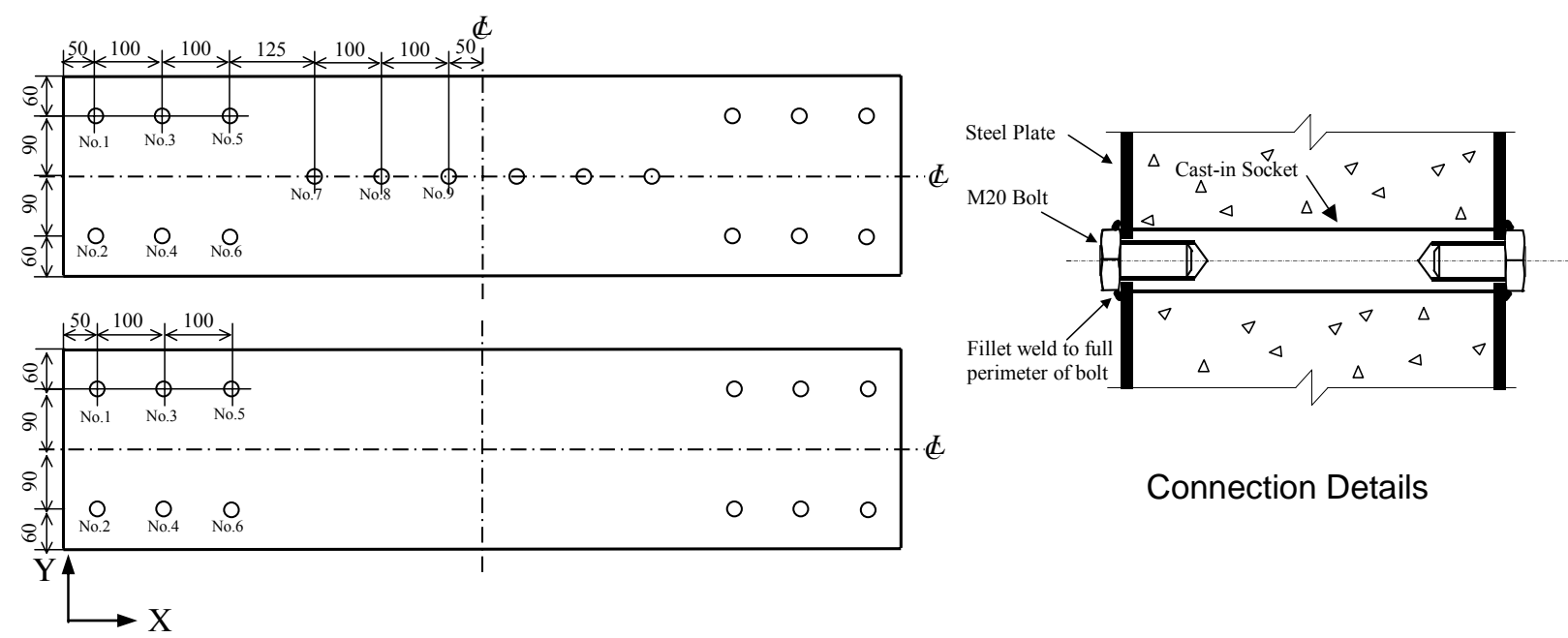

Figure 2. Steel Plates and Bolt Locations 


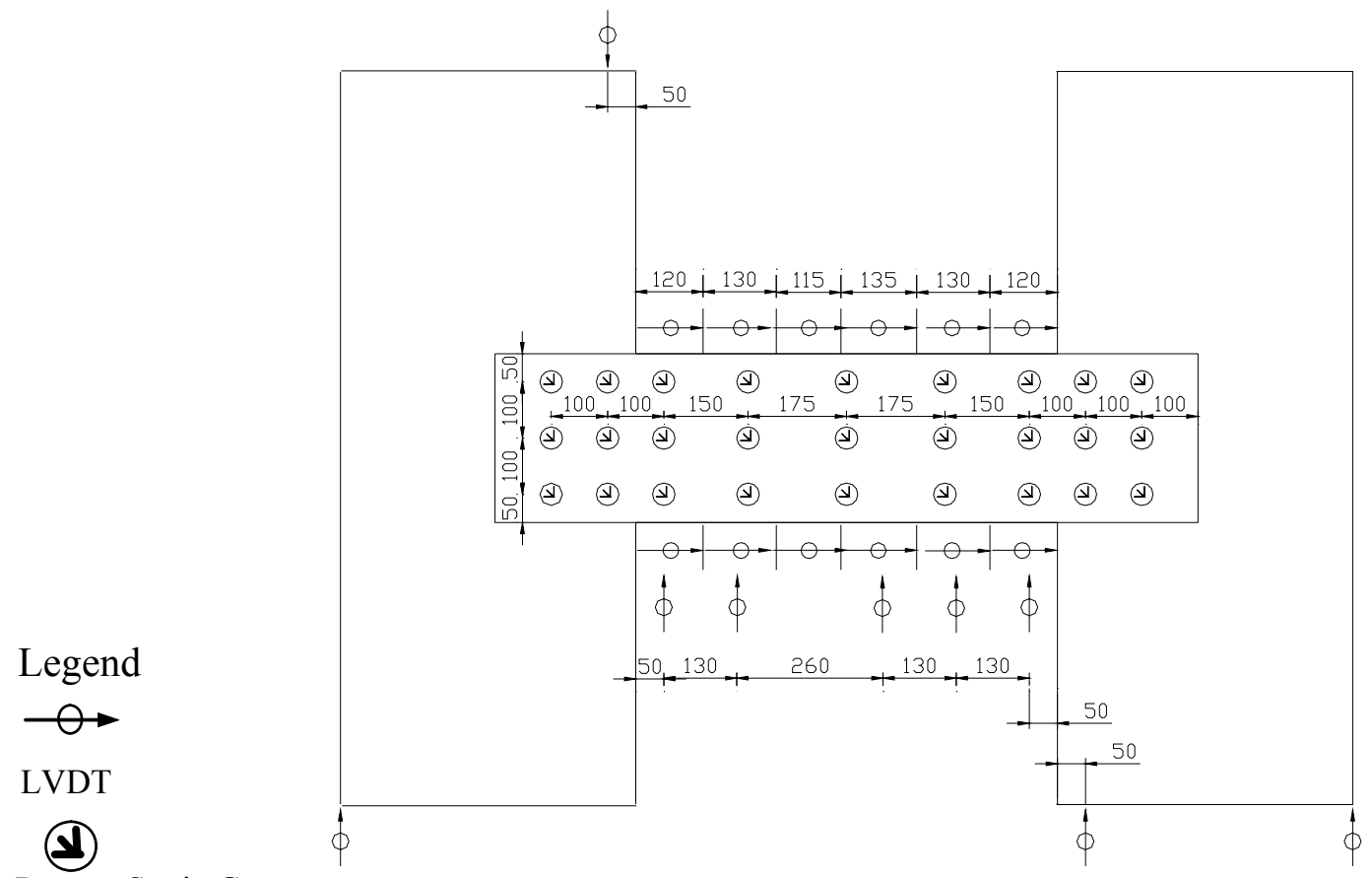

Rosette Strain Gauge

Figure 3. LVDTs and Rosette Strain Gauges Arrangement for CB3

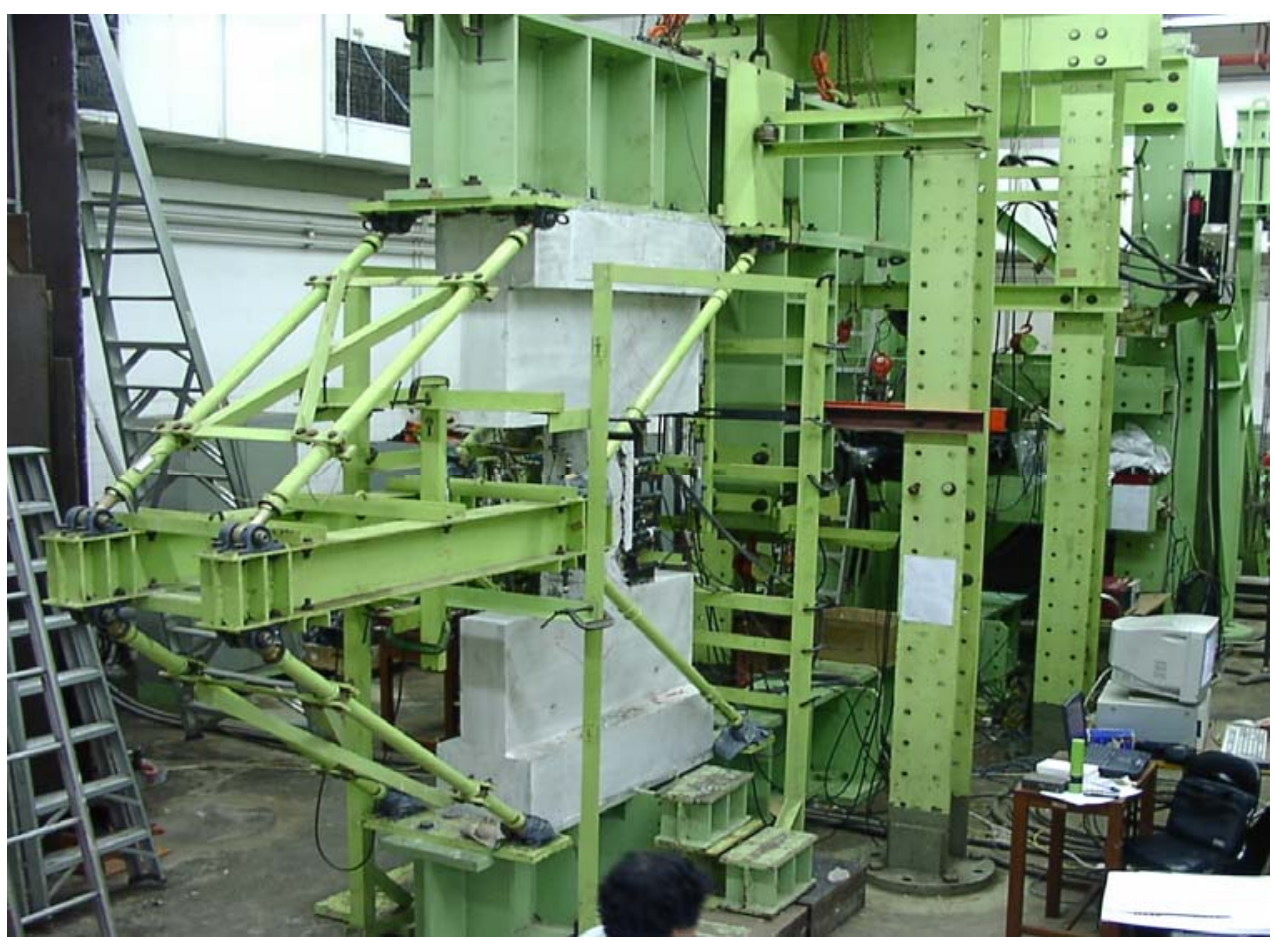

Figure 4. Photo of Test Setup 


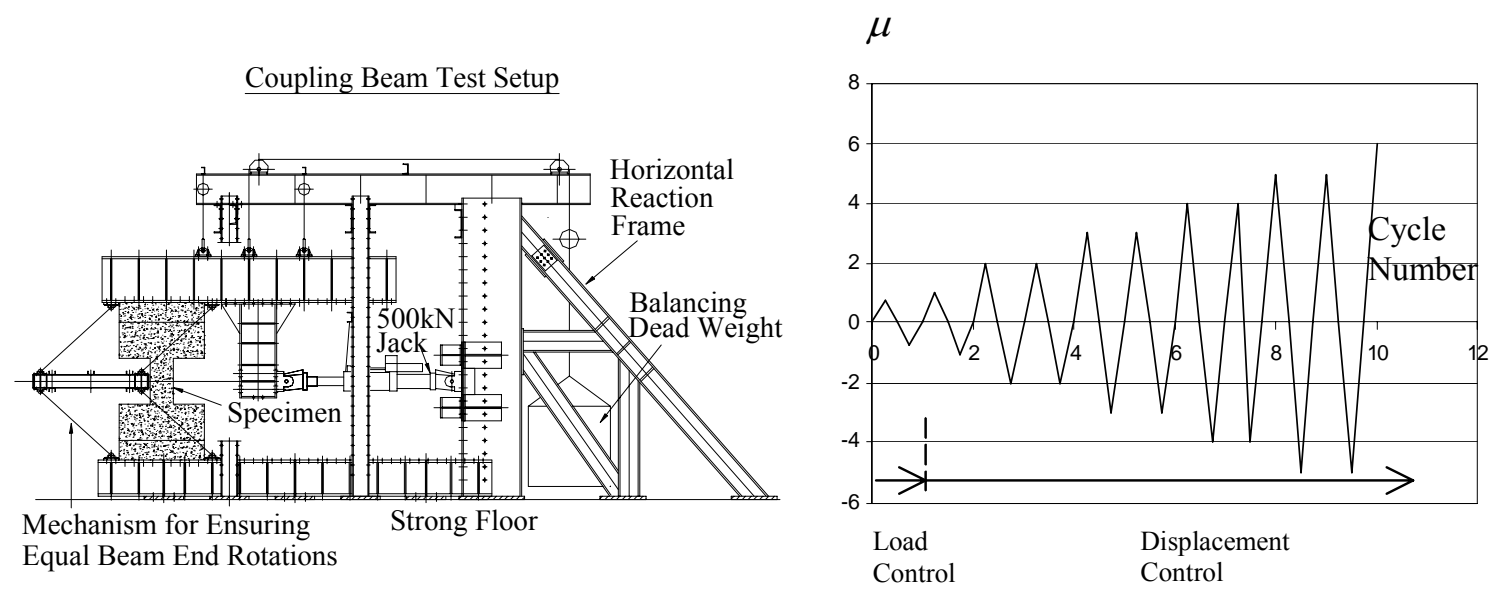

Figure 5. Test Setup and Load Program
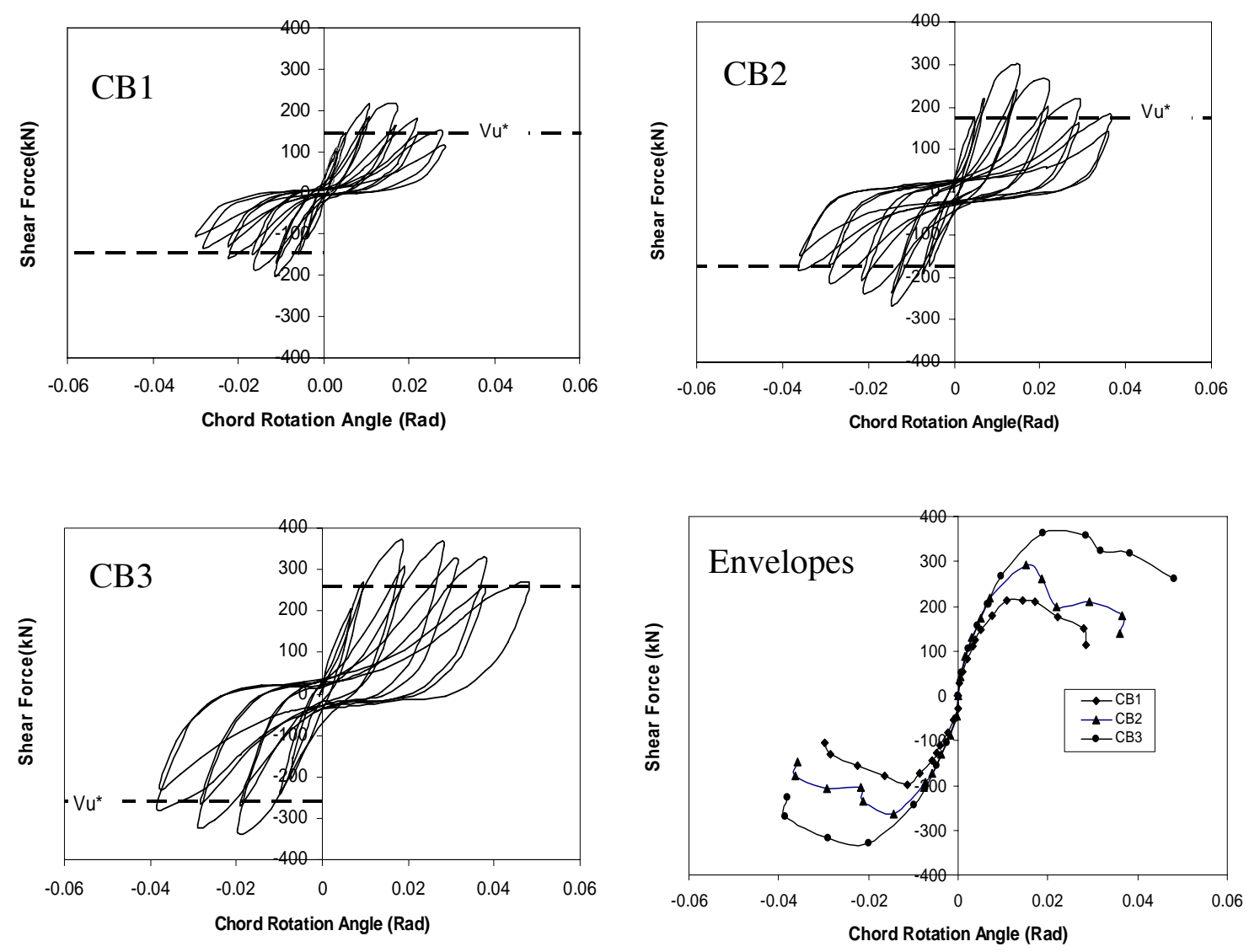

Figure 6. Load-Chord Rotation Hysteresis Loops and Envelope Curves 


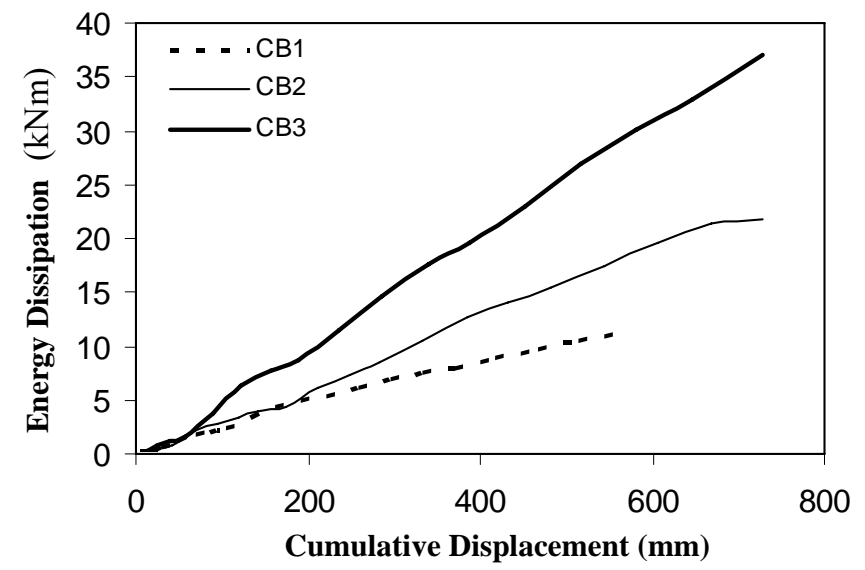

Figure 7. Energy Dissipation

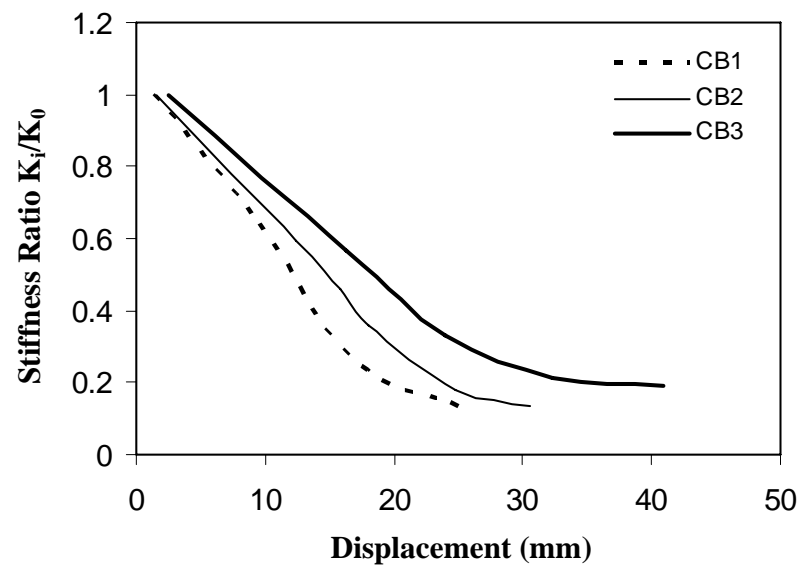

Figure 8. Degradation of Stiffness 

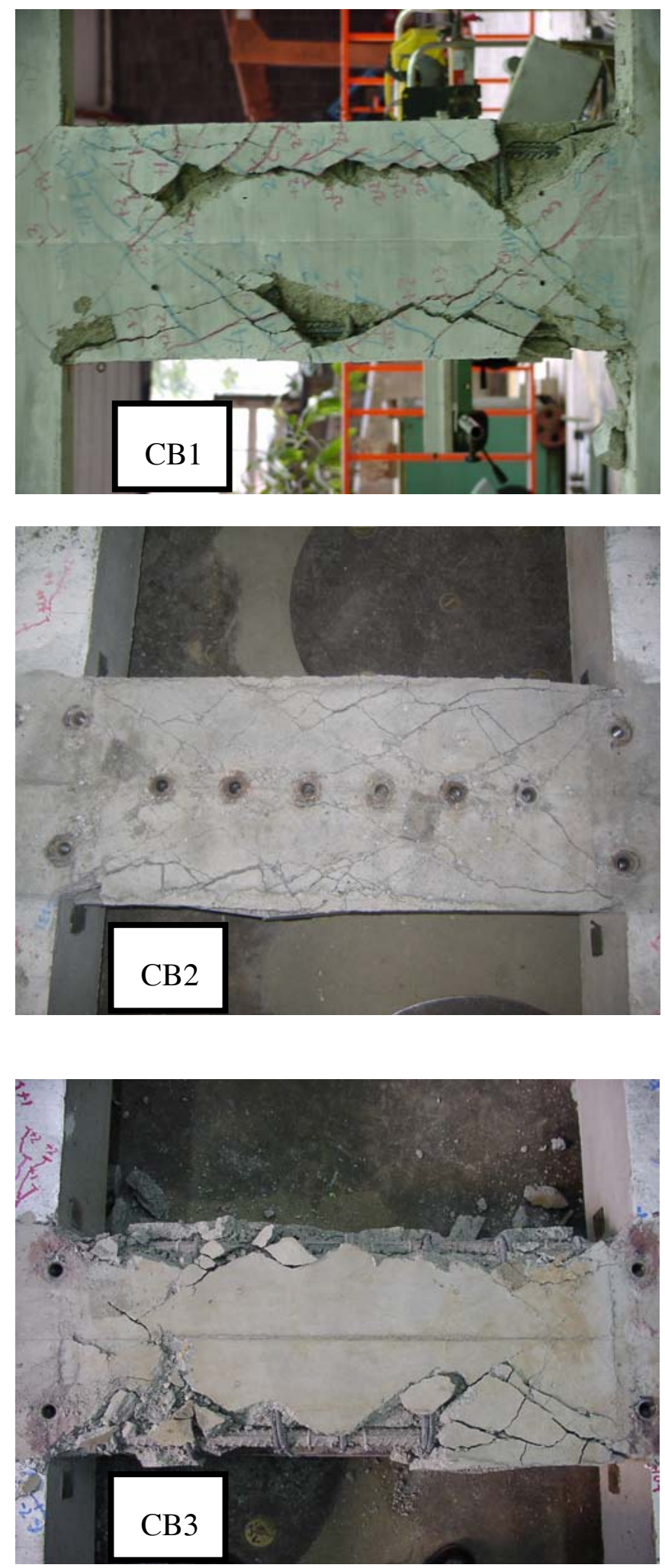

Figure 9. Specimens at Failure 


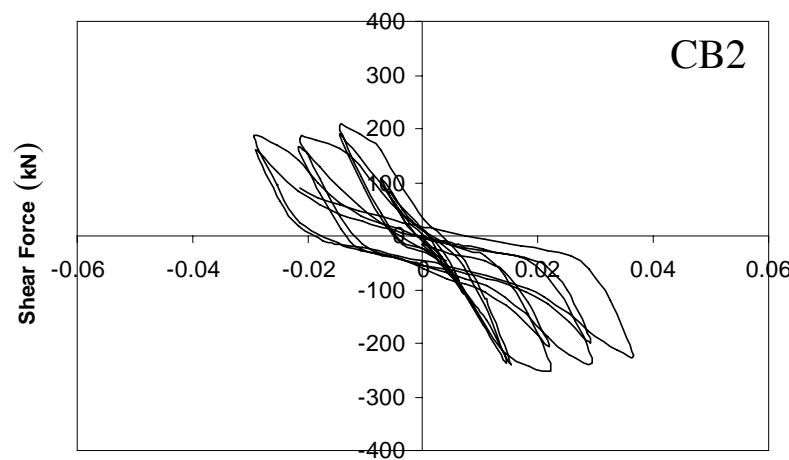

Chord Rotation Angle (Rad)

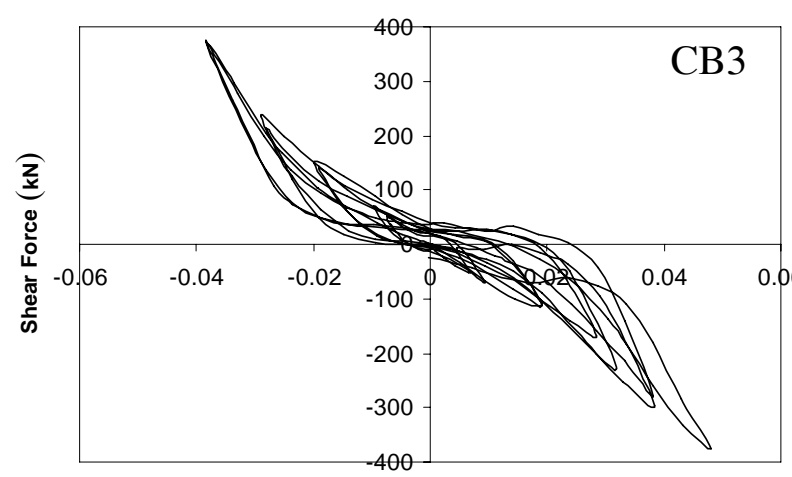

Chord Rotation Angle (Rad)
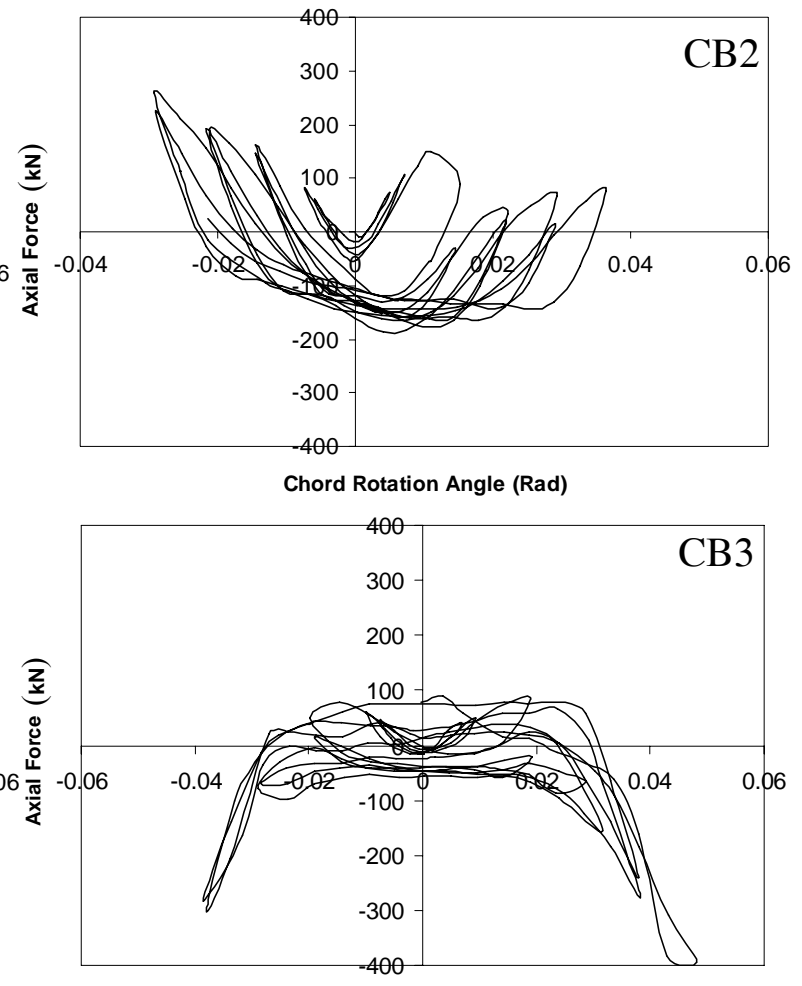

Chord Rotation Angle (Rad)

Figure 10. Steel Plate Section Internal Forces - Chord Rotation Angle Curves



CB2

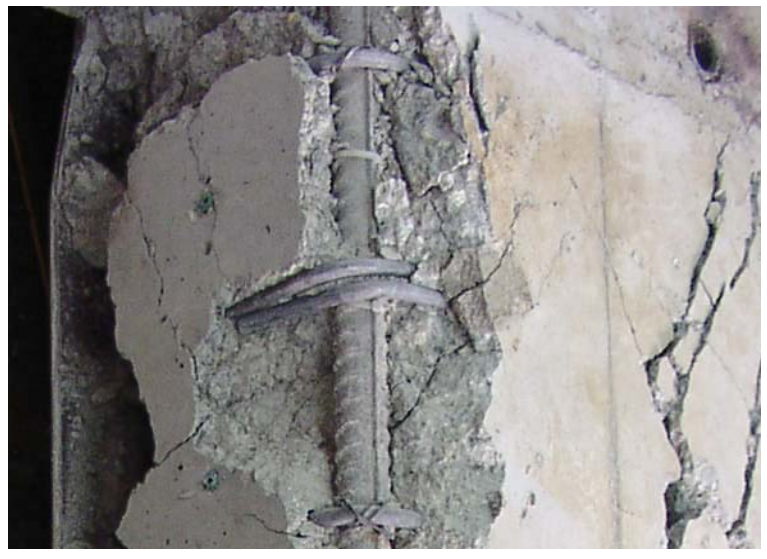

CB3

Figure 11. Local Buckling of Specimens at Failure Stage 


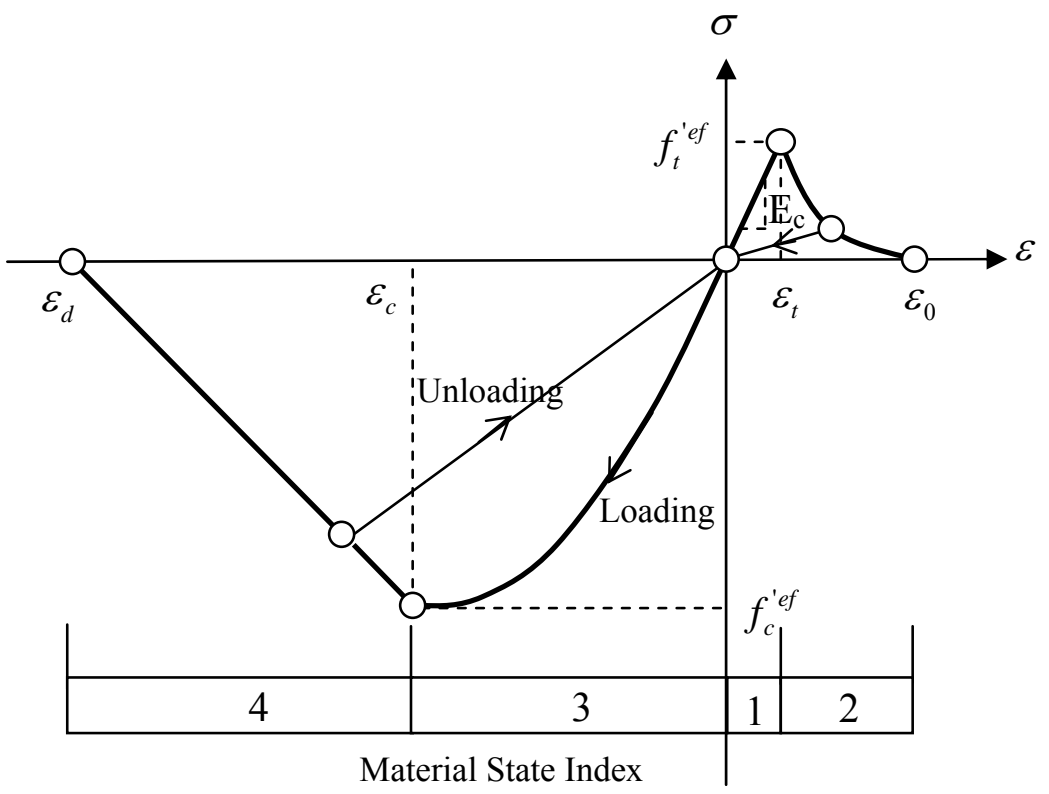

Figure 12. Uniaxial Stress-Strain Law for Concrete. 




Finite element model for a bolt

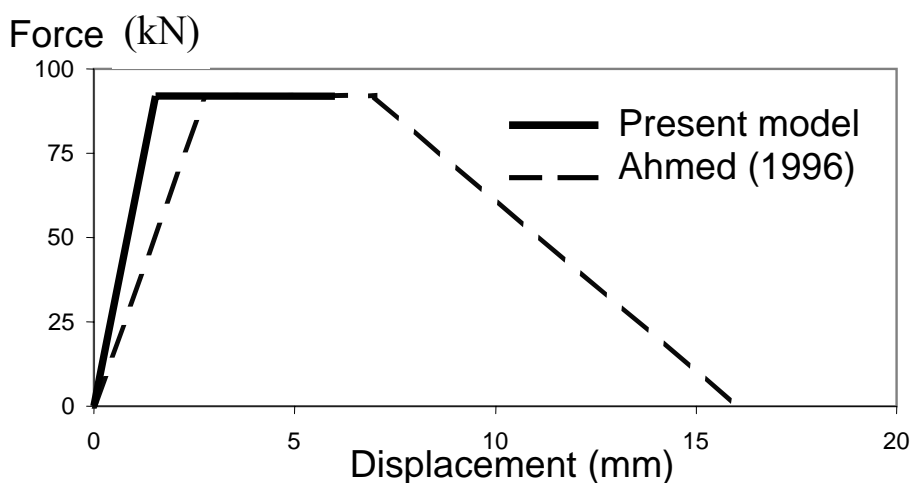

Figure 13: Load-slip Model of a Bolted Connection

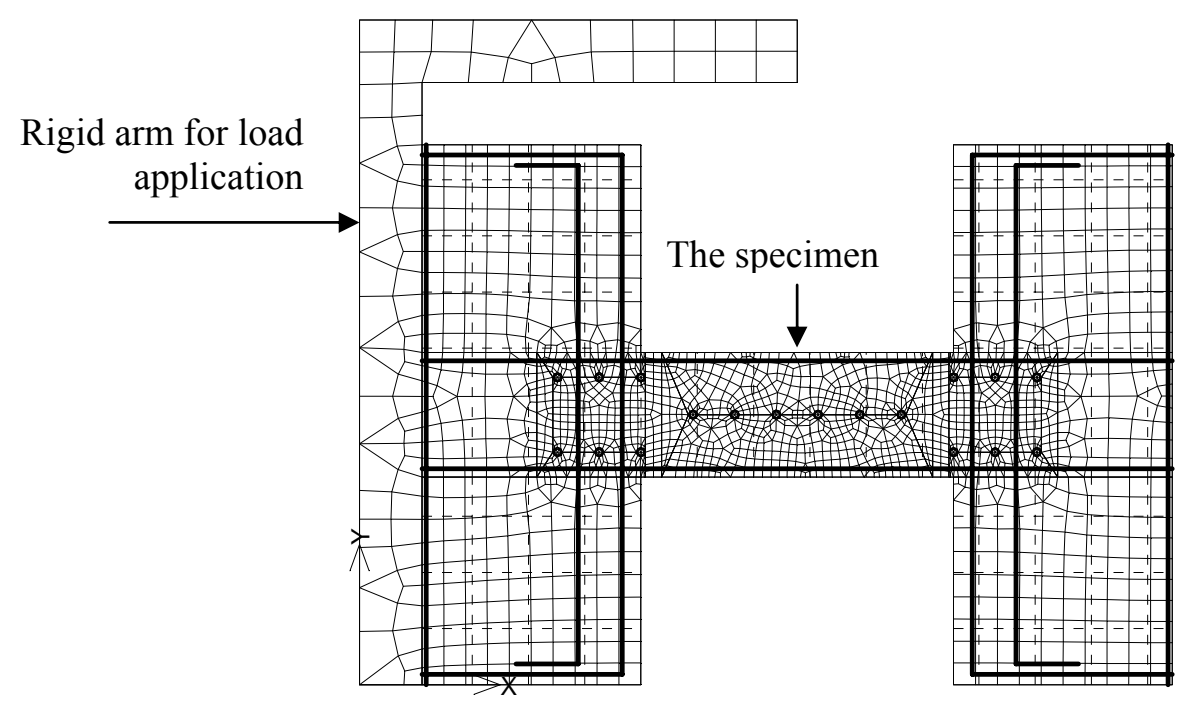

Figure 14: Mesh Configuration for Finite Element Analysis. 


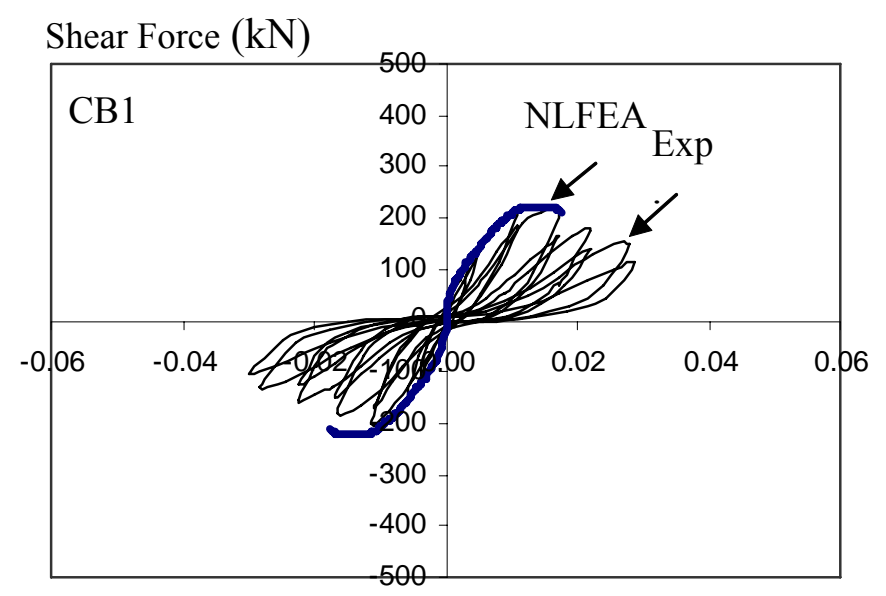

Chord Rotation Angle (Rad)

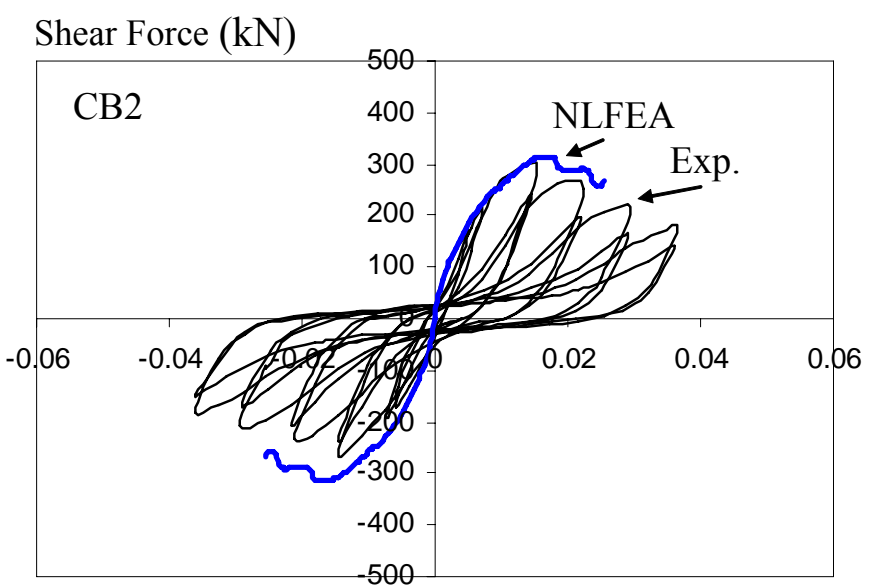

Chord Rotation Angle (Rad)

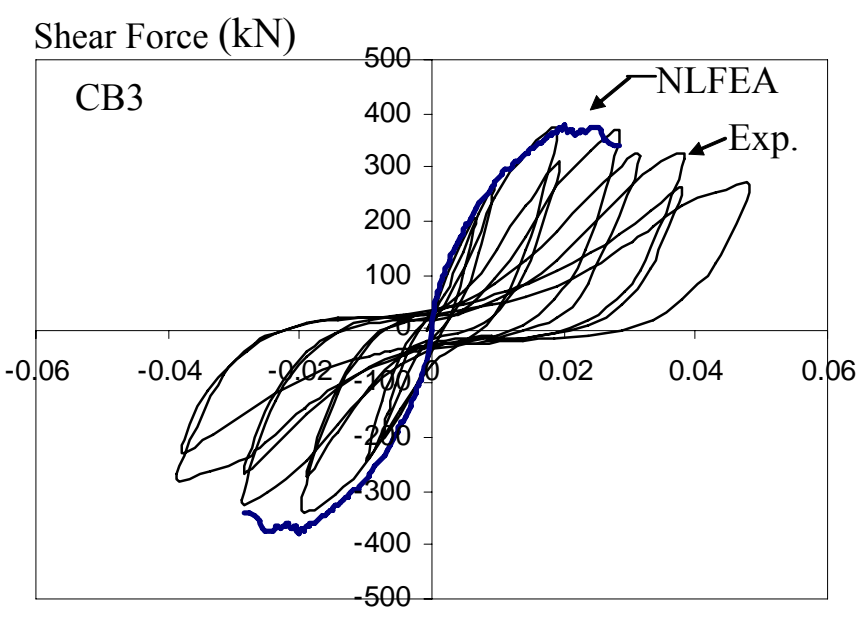

Chord Rotation Angle (Rad)

Figure 15: Shear Force-Chord Rotation Curves for CB1, CB2 and CB3 

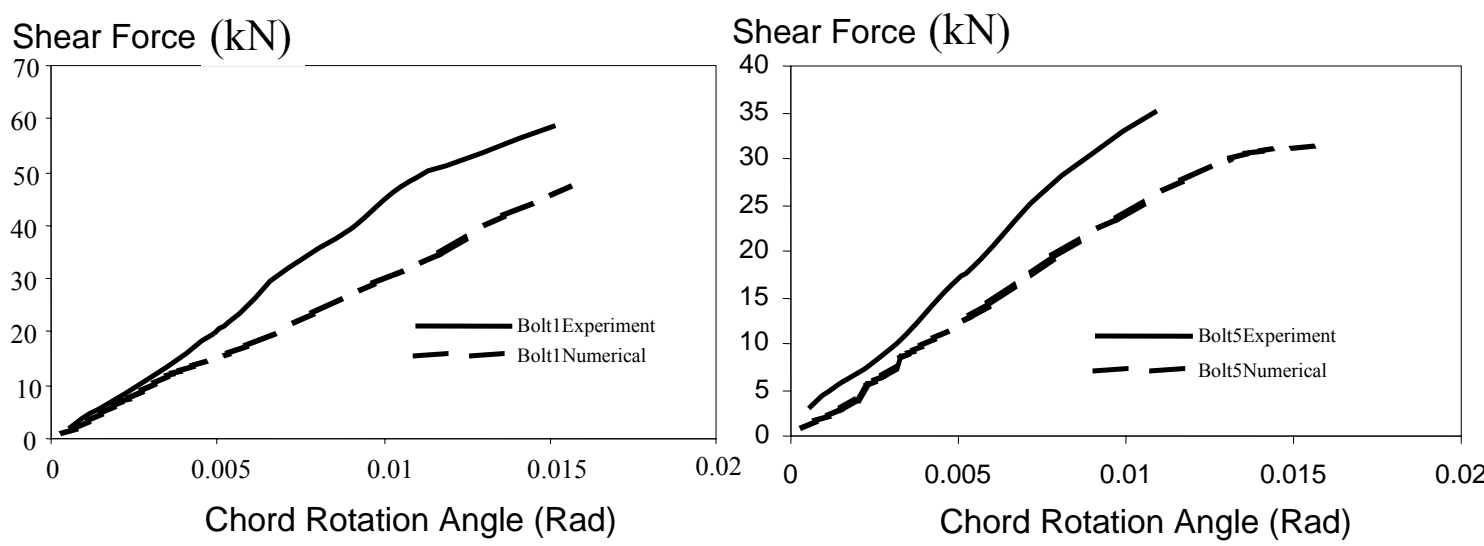

Figure 16: Comparison of the Numerical and Experimental Bolt Forces of CB2
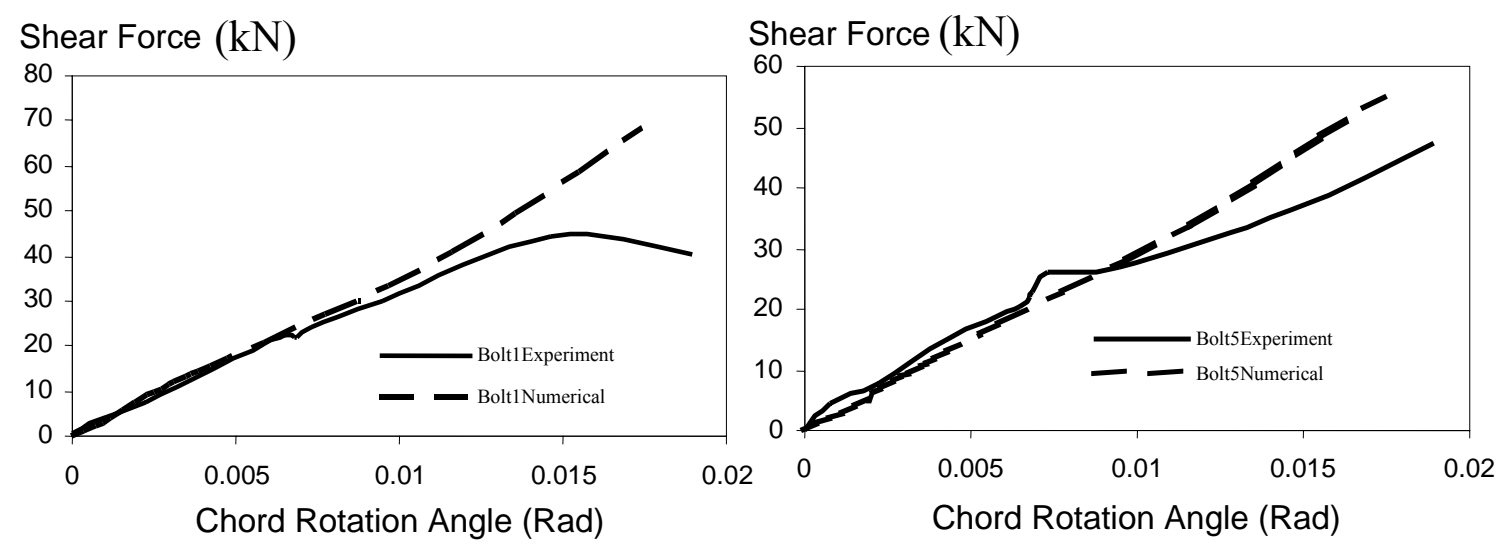

Figure 17: Comparison of the Numerical and Experimental Bolt Forces of CB3 


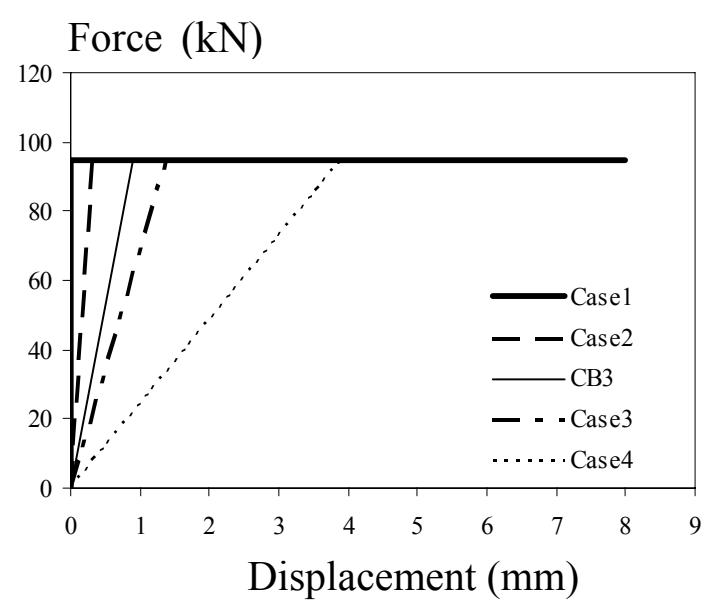

(a)

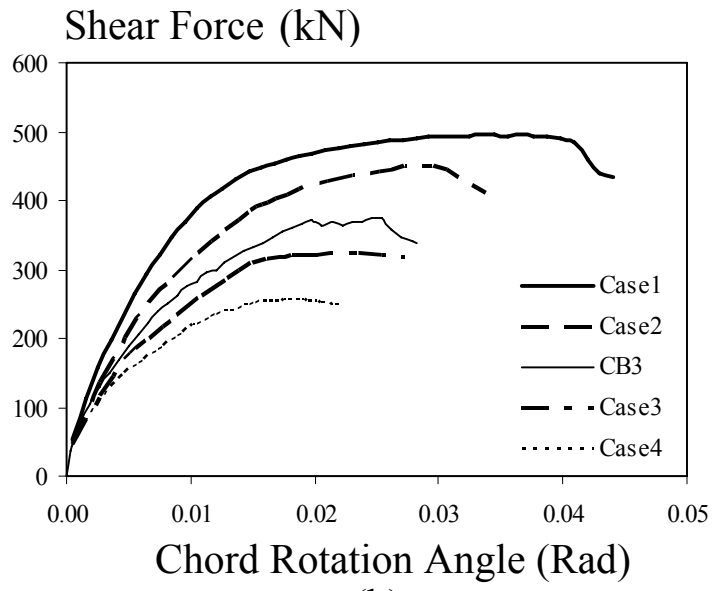

(b)

Figure 18: Effect of varying stiffness of bolt connection in CB3 
Table 1. Coupling Beam Details

\begin{tabular}{|c|c|c|c|}
\hline Beam & Span-Depth Ratio & Plate Thickness & Bolt Arrangement \\
\hline CB1 & 2.5 & N/A & N/A \\
\hline CB2 & 2.5 & $3 \mathrm{~mm}$ & At Ends and Span of the \\
& & & Plate \\
\hline CB3 & 2.5 & $6 \mathrm{~mm}$ & At Ends of the Plate \\
\hline
\end{tabular}

Table 2. Material Properties (MPa)

\begin{tabular}{|c|c|c|c|}
\hline & & $f_{c u}$ & $f_{c}^{\prime}$ \\
\hline \multirow{3}{*}{ Concrete } & CB1 & 50.2 & 43.9 \\
\hline & CB2 & 49.1 & 42.8 \\
\hline & CB3 & 44.3 & 42.6 \\
\hline \multicolumn{4}{|r|}{ Young's modulus } \\
\hline \multirow{5}{*}{ Steel Bar } & $\mathrm{R} 8$ & 462.7 & 212000 \\
\hline & T10 & 571.0 & 211000 \\
\hline & T12 & 529.3 & 207000 \\
\hline & T16 & 549.2 & 210000 \\
\hline & T20 & 504.1 & 203000 \\
\hline \multirow{2}{*}{ Steel Plate } & $3 \mathrm{~mm}$ & 342.0 & 185000 \\
\hline & $6 \mathrm{~mm}$ & 354.3 & 193000 \\
\hline
\end{tabular}


Table 3. Summary of Experimental Results

\begin{tabular}{|c|c|c|c|c|c|c|c|c|}
\hline Specimen & $\begin{array}{c}V_{u}^{*} \\
(\mathrm{kN})\end{array}$ & $\begin{array}{c}V_{\max } \\
(\mathrm{kN})\end{array}$ & $V_{\max } / V_{u}$ & $\begin{array}{c}\theta_{y n} \\
(\mathrm{rad})\end{array}$ & $\begin{array}{c}\theta_{y} \\
(\mathrm{rad})\end{array}$ & $\begin{array}{c}\theta_{u} \\
(\mathrm{rad})\end{array}$ & $\mu_{n}$ & $\mu$ \\
\hline $\mathrm{CB} 1$ & 151 & 213 & 1.4 & 0.0048 & 0.0078 & 0.0297 & 6.2 & 4.0 \\
\hline $\mathrm{CB} 2$ & 232 & 291 & 1.3 & 0.0072 & 0.0095 & 0.0365 & 5.1 & 3.8 \\
\hline $\mathrm{CB} 3$ & 274 & 363 & 1.3 & 0.0095 & 0.0129 & 0.0482 & 5.1 & 3.7 \\
\hline
\end{tabular}

Table 4a. Bolt Forces of Specimen CB2

\begin{tabular}{|c|c|c|c|c|c|c|c|c|c|}
\hline Force(kN) & Bolt1 & Bolt2 & Bolt3 & Bolt4 & Bolt5 & Bolt6 & Bolt7 & Bolt8 & Bolt9 \\
\hline X-Direction & -21.1 & -21.1 & 10.0 & 10.0 & 30.1 & 30.1 & -17.4 & -7.2 & -6.9 \\
\hline Y-Direction & 33.6 & 3.5 & 8.1 & -12.2 & -5.7 & 20.8 & -3.4 & 12.5 & -3.8 \\
\hline
\end{tabular}

Table 4b. Bolt Forces of Specimen CB3

\begin{tabular}{|c|c|c|c|c|c|c|}
\hline Force(kN) & Bolt1 & Bolt2 & Bolt3 & Bolt4 & Bolt5 & Bolt6 \\
\hline X-Direction & -14.2 & -14.3 & -23.2 & -23.2 & -21.3 & -21.3 \\
\hline Y-Direction & 35.5 & -25.5 & 5.9 & 23.4 & 3.2 & 28.6 \\
\hline
\end{tabular}

